Finisterra, XXXVII, 73, 2002, pp. 81-98

\title{
AS RECENTES ALTERAÇÕES NO CURRÍCULO OBRIGATÓRIO DE GEOGRAFIA EM PORTUGAL (1989-2001)
}

\author{
Maria Fernanda Alegria ${ }^{1}$
}

\begin{abstract}
Resumo - As duas recentes reformas do ensino obrigatório em Portugal (decretos 286/89 e 6/2001) tiveram implicações no ensino da Geografia. Alguns dos aspectos onde se verificaram alterações de 1989 para 2001 foram: a criação de aulas de 90 minutos, com diminuição da carga lectiva semanal de Geografia, a articulação de horários com a História, a leccionação de Geografia no $7 .^{\circ}, 8 .^{\circ}$ e $9 .^{\circ}$ ano desde 2001, quando em 1989 se interrompia no $8 .^{\circ}$ ano. Os conteúdos foram modificados, contrariamente ao que se previa de início. A noção de «competência», central na mais recente reforma, um resumo do sentido das três novas áreas curriculares ditas transversais (formação cívica, área de projecto e estudo acompanhado), bem como uma apreciação sobre a difusão da reforma no país, as vantagens e dificuldades de uma maior autonomia das escolas na gestão do currículo terminam a primeira parte. A discussão sobre a utilidade da Geografia no ensino obrigatório, a justificação de alguns recursos e uma apreciação sobre as virtudes e dificuldades da reforma de 2001 terminam este artigo.
\end{abstract}

Palavras-chave : ensino da Geografia, gestão do currículo, reformas curriculares.

Abstract - Recent Changes In Compulsory School Education Curriculum Of Geography In Portugal (1989-2001). The two recent reforms in compulsory school education in Portugal (decrees 286/89 and 6/2001) have affected geography teaching. Changes made between 1989 and 2001 included: setting up 90-minute classes with less geography teaching on a weekly basis; organising timetables with history classes; teaching geography at the 7th, 8th and 9th grade level since 2001, whereas in 1989 geography classes ceased at 8th grade. Curriculum contents were changed unlike what had been initially planned. The first part of the paper deals with the idea of 'competence', central to more recent educational reform, with a summary of the meaning of the three new so-called transversal curriculum items (civic training, project planning and structured learning), as well as with an understanding of the dissemination of educational reform throughout the country and the advantages and difficulties of schools being more autonomous in their curriculum organisation. The second part explores the usefulness of geography in compulsory education, the justification for some resources and an assessment of the qualities and difficulties of the 2001 reform.

Key words : geography teaching, curriculum management, curriculum reform.

1 Professora Associada da Universidade Nova de Lisboa e Investigadora do Centro de Estudos Geográficos. E-mail: mfalegria@netcabo.pt 
No momento em que este texto é escrito (finais do ano lectivo de 2001/ /2002), ainda não é conhecida a opinião do novo governo, que tomou posse em Abril de 2002, sobre a reforma do ensino obrigatório preparada pela anterior equipa ministerial. Enquanto as mudanças previstas para o ensino secundário foram desde logo rejeitadas ${ }^{2}$, as alterações curriculares do ensino básico, decretadas em 2001, foram assumidas, não se sabe se com efectiva concordância, ou se apenas porque elas já tinham sido iniciadas no $1 .^{\circ}$ e no $2 .^{\circ}$ ciclo e experimentadas no $3 .^{\circ}$ ciclo nalgumas escolas ${ }^{3}$. Este artigo analisa aspectos essenciais das reformas do ensino obrigatório de Geografia de 1989 e de 2001, o que, neste momento, tem bastante pertinência.

Uma distinção de fundo entre as duas reformas é que a equipa que preparou as alterações curriculares decretadas em 2001 apenas assumiu que iria incentivar algumas mudanças na "gestão do currículo", mantendo os programas disciplinares vigentes desde 1989, o que não aconteceu, pois os programas foram alterados.

Outra distinção, igualmente importante, tem a ver com a informação e preparação da classe docente. Enquanto a reforma de 1989 foi bastante divulgada e nalguns aspectos avaliada antes de ser posta em prática, a de 2001 é ainda hoje mal conhecida por muitos professores, alunos e encarregados de educação.

Para além destes aspectos gerais há outros que convém sublinhar, alguns deles positivos. Comecemos, no entanto, por informações mais básicas, para que os leitores menos conhecedores da realidade educativa portuguesa se possam situar.

Em Portugal é considerado obrigatório o ensino até ao $9 .^{\circ}$ ano de escolaridade, distribuído por 3 ciclos (Quadro I). Se o aluno reprovar, em um ou mais anos, tem de continuar a frequentar a escola até aos 16 anos, por vezes acedendo a currículos alternativos, mais simples e flexíveis do ponto de vista da exigência sobre determinados conteúdos.

A seguir ao $3 .^{\circ}$ ciclo, segue-se o "ensino secundário», $10 .^{\circ}, 11 .^{\circ}$ e $12 .^{\circ}$ anos (15-17 anos), onde a Geografia é opcional, ou seja, é frequentada facultativamente.

Neste texto, vamos cingir-nos ao ensino obrigatório e privilegiar o $3 .^{\circ}$ ciclo, já que as Universidades que formam docentes de Geografia se dirigem apenas a este ciclo e ao secundário e a reforma deste nível de ensino foi suspensa.

\footnotetext{
2 A recusa foi imediatamente assumida pelo Ministro da Educação; a suspensão formal foi feita pelo Decreto-Lei n. ${ }^{\circ}$ 156/2002.

3 A reforma de 2001 foi iniciada no $1 .^{\circ}$ e no $2 .^{\circ}$ ciclo em 2001/2002 e entrará em vigor no 7. ${ }^{\circ}$ ano em 2002/2003, no $8 .^{\circ}$ ano em 2003/2004 e no ano lectivo seguinte no $9 .^{\circ}$ ano.
} 
Quadro I - A escolaridade obrigatória em Portugal: ciclos e idades etárias.

Table I-Compulsory school education in Portugal: primary, preparatory and secondary school education (ciclos) and ages.

\begin{tabular}{|c|c|c|}
\hline Ciclos & N. ${ }^{\circ}$ de anos lectivos & Idade dos alunos (sem reprovação) \\
\hline $1 .^{\circ}$ ciclo & 4 & $6-9$ anos \\
\hline $2 .^{\circ}$ ciclo & 2 & $10-11$ anos \\
\hline $3 .^{\circ}$ ciclo & 3 & $12-14$ anos \\
\hline
\end{tabular}

Nos dois decretos (286/89 e 6/2001) há certas permanências. São exemplos, entre outros, o número de anos de cada um dos 3 ciclos obrigatórios e a integração da Geografia em certas áreas curriculares em dois dos 3 ciclos obrigatórios (Quadro II).

Quadro II - Alterações no ensino obrigatório de 1989 para 2001.

Relação da Geografia com outras disciplinas.

Table II-Changes in compulsory school education between 1989 and 2001. Integration of geography with other subjects.

\begin{tabular}{|c|c|c|c|}
\hline Os ciclos & Anos lectivos & Os temas & $\begin{array}{c}\text { Relação da Geografia com outras } \\
\text { disciplinas em 1989 e em 2001 }\end{array}$ \\
\hline $\begin{array}{c}1 .^{\circ} \text { ciclo } \\
6-9 \text { anos }\end{array}$ & $1 .^{\circ}, 2 .^{\circ}, 3 .^{\circ}$ e $4 .^{\circ}$ & Meio local & $\begin{array}{c}\text { Ciências Sociais? } \\
\text { (relação vaga, em 1989 e em 2001) }\end{array}$ \\
\hline $\begin{array}{c}2 .^{\circ} \text { ciclo } \\
10-11 \text { anos }\end{array}$ & $5 .^{\circ}$ e $6 .^{\circ}$ & História e Geografia de Portugal & História (em 1989 e em 2001) \\
\hline $\begin{array}{c}3 .^{\circ} \text { ciclo } \\
12-14 \text { anos }\end{array}$ & $7 .^{\circ}, 8 .^{\circ}$ e 9. & Geografia da Europa e do Mundo & $\begin{array}{c}\text { Geografia autónoma em 1989, } \\
\text { com horários articulados com } \\
\text { História em 2001 }\end{array}$ \\
\hline
\end{tabular}

Como se vê, mantém-se no $2 .^{\circ}$ ciclo a ligação privilegiada à História. No $3 .^{\circ}$ ciclo a disciplina de Geografia, que era autónoma em 1989, mas apenas leccionada no $7 .^{\circ}$ e no $9 .^{\circ}$ ano, passa a partilhar horários com a História. As formas de dividir as cargas lectivas atribuídas à "área de Geografia e História» são tomadas por cada escola, no âmbito da "gestão flexível do currículo", a que a seguir nos referiremos. Mas as relações entre as duas disciplinas quase se restringem a essa partilha de horas, o que é pouco.

Além desta, há alterações de certo modo importantes de 1989 para 2001, de que vamos a seguir dar notícia. 
Quadro III - Carga lectiva semanal da Geografia e de disciplinas da mesma 'área disciplinar' em 1989 (A cada aula semanal correspondem tempos de 50 minutos).

Table III - Weekly classes of geography and other subjects within the same 'subject group' in 1989 (50-minute classes).

\begin{tabular}{|l|c|c|c|c|c|c|}
\hline \multicolumn{1}{|c|}{ Ciclos e disciplinas } & $5 .^{\circ}$ ano & $6 .^{\circ}$ ano & $7 .^{\circ}$ ano & $8 .^{\circ}$ ano & $9 .^{\circ}$ ano & Total no ciclo \\
\hline \begin{tabular}{l}
$2^{\circ}$ ciclo (área disciplinar) $_{\text {História e Geografia de Portugal }}$ \\
\hline $\begin{array}{l}3 .^{\circ} \text { ciclo } \\
\text { Geografia da Europa }\end{array}$
\end{tabular} & 3 & & & & & $\begin{array}{c}6 \text { aulas } \\
\text { de } 50 \text { minutos } \\
\text { (2 disciplinas) }\end{array}$ \\
\hline Geografia Mundial & 3 & 0 & 4 horas & $\begin{array}{c}7 \text { de } 50 \text { minutos } \\
\text { (só Geografia) }\end{array}$ \\
\hline
\end{tabular}

Para não nos alongarmos nos comentários, registe-se apenas que, pelo decreto 286/89, a Geografia partilhava com a História, no 2. ${ }^{\circ}$ ciclo, 6 horas lectivas por semana (com aulas de 50 minutos); no $3 .^{\circ}$ ciclo, Geografia e História eram disciplinas independentes com 7 horas lectivas cada uma (Quadro III).

Alguns dos grandes objectivos da reforma de 2001 foram limitar o número de horas de presença dos alunos na escola, reduzir as horas de frequência de disciplinas, para se diversificarem matérias, criando outras mais transversais. Essas novas áreas curriculares, a que adiante faremos referência, são «O Estudo Acompanhado», "A Formação Cívica» e «A Área de Projecto».

O decreto 6/2001 não define cargas lectivas por disciplina, mas por áreas disciplinares. A divisão dos tempos lectivos pelas disciplinas de cada área fica a cargo das escolas. Muitas das que aderiram à chamada experiência de «gestão flexível do currículo» ${ }^{4}$ optaram por uma divisão equitativa, criando aulas de 45 minutos.

Admitindo a hipótese da divisão equitativa, a Geografia passou a dispor, no $3 .^{\circ}$ ciclo, a partir de 2001 , de 5,25 horas $(2+2,5+2,5=7 \times 90$ minutos $=$ 630 minutos: 60 minutos $=10,5$ horas: $2=5,25$ horas), contra 7 horas em 1989 (Quadro IV). Esta diminuição das cargas lectivas tem sido muito polémica entre docentes. A desvalorização da Geografia como disciplina essencial da formação dos jovens, com as perspectivas de desemprego associadas, são difíceis de aceitar.

4 Os primeiros ensaios de "gestão flexível do currículo» iniciaram-se em 1997/98, com 10 escolas. Em 1998/99 aderiram 33 escolas, no ano seguinte, 93, e a seguir, 184, num universo de 8.500 escolas. 
Quadro IV - Carga lectiva semanal da Geografia e de disciplinas da mesma 'área disciplinar' em 2001 (A cada aula semanal correspondem tempos de 90 minutos).

Table IV-Weekly classes of geography and other subjects within the same 'subject group' in 2001 (90-minute classes).

\begin{tabular}{|c|c|c|c|c|c|c|}
\hline Ciclos e áreas disciplinares & $5 .^{\circ}$ ano & $6 .^{\circ}$ ano & $7 .^{\circ}$ ano & $8 .^{\circ}$ ano & $9 .^{\circ}$ ano & Total no ciclo \\
\hline $\begin{array}{l}2 .^{\circ} \text { ciclo (área disciplinar de Lín- } \\
\text { guas e Estudos Sociais): Língua } \\
\text { portuguesa, Língua estrangeira e } \\
\text { História e Geografia de Portugal }\end{array}$ & 5,0 & 5,5 & & & & \\
\hline $\begin{array}{l}3 .^{\circ} \text { ciclo (área disciplinar de } \\
\text { Ciências Humanas e Sociais): } \\
\text { História e Geografia }\end{array}$ & & 2 & 2,5 & 2,5 & $\begin{array}{c}\text { aulas } \\
\text { (3 disciplinas })\end{array}$ \\
\hline
\end{tabular}

Ainda que o Ministério da Educação afirme que a redução do número de horas lectivas de algumas disciplinas é "compensada» com cargas horárias nas chamadas "áreas transversais», isso não é suficiente para reparar as grandes perdas de algumas disciplinas, como a História e a Geografia. Além disso, como a partir de 2001 passaram a ser as escolas a decidir a distribuição de uma boa parte das cargas lectivas, os professores ainda não efectivos numa dada escola e disciplina ficam numa grande incerteza, já cada centro escolar gere como entender as horas de diversas áreas disciplinares e das áreas transversais não disciplinares. As escolas dispõem ainda de 90 minutos no $2 .^{\circ}$ ciclo e de 135 minutos no $3 .^{\circ}$ ciclo para distribuir como quiserem.

Uma vantagem indiscutível do decreto de 2001 está no facto de a Geografia ser leccionada no $7 .^{\circ}$, no $8 .^{\circ}$ e no $9 .^{\circ}$ ano, acabando-se com a interrupção do ensino no $8 .^{\circ}$ ano decretada em 1989. Numa lógica de aprendizagem por ciclo (que teoricamente já existia em 1989) as interrupções não têm qualquer sentido.

Porque os programas de Geografia em vigor desde 1989 só se alteram no ano lectivo de 2002/2003 no que ao $7 .^{\circ}$ ano de escolaridade diz respeito, e para serem melhor compreendidas as alterações decretadas em 2001, relembremos rapidamente os grandes temas (quadros V, VI e VII).

No $1 .^{\circ}$ tema, as 18 horas são constantemente excedidas. No geral ocupa-se mais do dobro das aulas. No $2 .^{\circ}$ tema, o estudo da população preenche a maior parte das aulas. Nos outros capítulos - cidades, espaços rurais e industriais, comércio, etc., os conceitos são complexos. O tema qualidade de vida em muitas escolas não é leccionado; noutras, tenta fazer-se a ligação ao seguinte, nem sempre com êxito. Como a interpretação dos programas (que eram muito genéricos) foi feita pelos manuais (que os docentes utilizam como recurso essencial e muitos alunos como fonte de informação quase única), podemos ainda afirmar 
Quadro V - Sumário dos conteúdos curriculares da Geografia no 7. ${ }^{\circ}$ ano desde 1989.

Table V-Summary of geography curriculum in the 7th grade in 1989.

\begin{tabular}{|l|c|}
\hline \multicolumn{1}{|c|}{$\begin{array}{c}\text { Temas do } 7 .^{\circ} \text { ano } \\
\text { (Europa) }\end{array}$} & $\begin{array}{c}\text { Gestão do tempo } \\
\text { (número de aulas de 60 min.) }\end{array}$ \\
\hline A Europa: dimensões e fronteiras & 18 \\
\hline Contrastes espaciais na organização do território; mobilidades (...) & 44 \\
\hline Qualidade de vida & 12 \\
\hline Equilíbrio ambiental & 12 \\
\hline
\end{tabular}

Quadro VI - Sumário dos conteúdos curriculares da Geografia no 9. ${ }^{\circ}$ ano em 1989.

Table VI-Summary of geography curriculum in the 9th grade in 1989.

\begin{tabular}{|l|c|}
\hline \multicolumn{1}{|c|}{$\begin{array}{c}\text { Temas do 9. }{ }^{\circ} \text { ano } \\
\text { (Mundo) }\end{array}$} & $\begin{array}{c}\text { Gestão do tempo } \\
\text { (número de aulas de 60 min.) }\end{array}$ \\
\hline A população e os recursos & 40 \\
\hline A interdependência mundial & 18 \\
\hline Desigualdades de níveis de desenvolvimento & 30 \\
\hline Equilíbrio ambiental & 30 \\
\hline
\end{tabular}

que, em parte do tema 2 e nos temas 3 e 4, as referências espaciais à Europa são escassas, o que na disciplina de Geografia é, no mínimo, estranho.

No $1 .^{\circ}$ tema, as 40 aulas previstas são muitas vezes excedidas por vários motivos: o tema já existia em programas anteriores, é mais fácil de leccionar do que outros deste programa, e é melhor tratado na maioria dos manuais. $\mathrm{O} 2 .^{\circ}$ tema, que inclui transportes, comunicações e comércio está no geral mal estruturado; em parte retomam-se temas do $7 .^{\circ}$ ano. O 3..$^{\circ}$ tema está também mal organizado. Devia ser um assunto sugestivo, mas é monótono, em parte porque se repetem conteúdos do $7 .^{\circ}$ ano, como qualidade de vida e bem estar. Fica a ideia de déjà $v u$. A maioria dos docentes de Geografia sente-se pouco à vontade no último tema, que inclui conceitos de Geografia Física. Por vezes não é leccionado.

Mais do que a crítica à repetição de certos temas, talvez valha a pena referir que impor o estudo de certos espaços, apresentados como ilhas, para analisar fenómenos geográficos é adulterar a noção de escala. Esta só pode ser entendida pela análise e comparação de fenómenos em diferentes espaços e dimensões, o que, no caso da Geografia da Europa não acontece. Na realidade, 
a Europa é estudada como um espaço autónomo, sem que sejam evidenciadas quaisquer relações com outros continentes ou espaços geográficos.

Na reforma curricular de 2001 dizia-se não haver novos programas a cumprir, mas orientações curriculares a respeitar. Esta indicação reveste-se de alguma ambiguidade: qual será a diferença entre novos «programas» e «orientações curriculares»? Na realidade, verificaram-se, de facto, alterações nos conteúdos programáticos e não apenas nas formas de gerir o currículo (Quadro VII).

Quadro VII - Conteúdos curriculares da Geografia no 3. ${ }^{\circ}$ ciclo, a partir de 2001.

Table VII - Geography curriculum in the 3rd cycle (secondary education) since 2001.

Temas propostos pelo Ministério da Educação

(sem indicação dos anos: $7 .^{\circ}, 8^{\circ}$ ou $9 .^{\circ}$ )

1. A Terra: estudos e representações

2. O meio natural

3. População e povoamento

4. Actividades económicas

5. Contrastes de desenvolvimento

6. Ambiente e sociedade

Teoricamente, a sequência dos temas de estudo propostos para os 3 anos do $3 .^{\circ}$ ciclo será feita por cada escola. No que diz respeito à Geografia há que respeitar uma condição: o tema "A Terra: estudos e representações» é obrigatoriamente o primeiro. Também é reconhecido que os dois últimos temas, pela maior complexidade, devem ser leccionados no $9 .^{\circ}$ ano. A margem de liberdade de cada escola fica assim bastante reduzida: apenas a decisão se os temas $2,3 \mathrm{e}$ 4 serão leccionados no $7 .^{\circ}$ ou no $8 .^{\circ}$ ano.

Quanto aos conteúdos de cada tema, refiram-se de forma sumária:

No tema 1. "A Terra: estudos e representações»; descrevem-se paisagens, localizam-se elementos da superfície terrestre e aprende-se a utilizar mapas. No tema 2. "O meio natural»; estuda-se o clima e as formações vegetais, o relevo, os riscos e catástrofes à escala do País e do Mundo. No tema 3. «População e povoamento"; estuda-se a evolução e distribuição da população, as migrações, a diversidade cultural, os meios urbanos e rurais. Nas «Actividades económicas», tema 4; trata-se de agricultura e pesca, indústria, serviços e turismo, impactes ambientais e sociais das actividades económicas e, ainda, dos transportes e comunicações. Nos "Contrastes de desenvolvimento», tema 5; comparam-se países desenvolvidos e países em desenvolvimento e a interdependência entre espaços. O tema 6 "Ambiente e sociedade»; trata dos desafios ambientais e do património. 
Como se depreende, persistem demasiados conteúdos. Nestas condições conseguir-se-ão desenvolver competências nos alunos, ou seja, a capacidade de utilizar saberes em condições diversificadas?

\section{A «GESTÃO FLEXÍVEL DO CURRÍCULO»}

Como se referiu, o poder político não assumiu de início que iria desencadear uma nova reforma curricular, que acabou por ser decretada em 2001. Começou por falar de "gestão flexível do currículo», entendida como a partilha de certas responsabilidades entre o poder central e as escolas.

As atribuições da administração central são as seguintes: indicar as cargas horárias de áreas disciplinares e disciplinas; definir as "competências gerais», que correspondem ao perfil do aluno à saída do ensino básico; definir as «competências específicas» das disciplinas obrigatórias.

Destas três atribuições, já nos referimos à primeira. Quanto às «competências gerais», foram definidas dez. Como é uma longa lista transcrevemo-la em nota de rodapé ${ }^{5}$, classificando-a nalgumas categorias essenciais: duas competências relativas à cultura, ciência e tecnologia (1 e 2), duas relativas ao domínio de línguas (3 e 4), duas ligadas às metodologias de organização da informação (5 e 6), duas competências relativas a atitudes (7 e 9), uma relacionada com a capacidade de agir (8) e, finalmente, também uma relativa ao domínio psico-motor (10). Analisando esta lista verifica-se que se fica num terreno tão vago, que não se vislumbra a sua utilidade. Para que serve, realmente, a definição deste tipo de compe-tências no quotidiano dos docentes? Do meu ponto de vista, para quase nada.

Quanto à terceira atribuição, que é a de definir as «competências específicas» das disciplinas obrigatórias, refere-se a seguir o caso da Geografia. Mas antes vejamos rapidamente as atribuições das escolas: gerir a carga horária das áreas disciplinares; decidir o melhor momento para leccionar certos conteúdos; gerir as «competências gerais» e as «competências específicas» das disciplinas; distribuir as cargas lectivas dos professores pelas novas áreas curriculares obrigatórias e transversais: Área de Projecto, Estudo Acompanhado, Formação Cívica.

5 «(1) Mobilizar saberes culturais, científicos e tecnológicos para compreender a realidade e para abordar situações e problemas do quotidiano; (2) Usar adequadamente linguagens das diferentes áreas do saber cultural, científico e tecnológico para se expressar; (3) Usar correctamente a língua portuguesa para comunicar de forma adequada e para estruturar pensamento próprio; (4) Usar línguas estrangeiras para comunicar adequadamente em situações do quotidiano e para apropriação de informação; (5) Adoptar metodologias personalizadas de trabalho e de aprendizagem adequadas a objectivos visados; (6) Pesquisar, seleccionar e organizar informação para a transformar em conhecimento mobilizável; (7) Adoptar estratégias adequadas à resolução de problemas e à tomada de decisões; (8) Realizar actividades de forma autónoma, responsável e criativa; (9) Cooperar com outros em tarefas e projectos comuns; (10) Relacionar harmoniosamente o corpo com o espaço, numa perspectiva pessoal e interpessoal promotora da saúde e da qualidade de vida». 
Nalgumas escolas tem-se procurado uma divisão equitativa da carga horária entre a História e a Geografia; noutras tem-se tentado que nalgumas aulas estejam presentes na sala, simultaneamente, professores de Geografia e de História.

Não tenho um conhecimento presencial dessas situações, mas apenas informações indirectas que me levam a crer que a ideia seria muito interessante, se os professores das duas disciplinas tivessem recebido formação nas duas áreas de conhecimento, o que não acontece em Portugal. O que parece estar a acontecer, quando os docentes de Geografia e História estão na mesma classe, é que a ajuda se limita à presença de outro docente na sala de aula, dando algum apoio aos alunos, quando se sentem preparados para isso.

A interdisciplinaridade é muito apregoada, tanto pelo poder central como pelas escolas. Todavia, para ela ser efectiva e útil, são precisos docentes preparados em áreas disciplinares distintas, o que não acontece na maioria dos cursos das universidades portuguesas.

Outros propósitos da "gestão flexível do currículo», que lentamente se foram conhecendo, são a concretização do currículo como um projecto da escola e da turma, procurando-se que os professores não sejam consumidores de currículos e gestores de programas decididos por outros, mas parceiros intervenientes em projectos educativos flexíveis e participados. A viabilidade destas intenções será avaliada mais tarde.

\section{As competências geográficas}

O livro Currículo Nacional do Ensino Básico. Competências essenciais, editado em 2001, procura esclarecer o que se entende por "competência», em princípio uma noção central na reforma de 2001.

Procurando retomar as ideias principais, bastante próximas das de Perrenoud (1998a e b, 1999, 2000a e b), considera-se que esta noção «integra conhecimentos, capacidades e atitudes e que pode ser entendida como saber em acção ou em uso (...). A noção de competência aproxima-se do conceito de literacia. A cultura geral que todos devem desenvolver como consequência da sua passagem pela educação básica [que] não se identifica com o conhecimento memorizado de termos, factos e procedimentos básicos (...). A competência diz respeito ao processo de activar recursos (...) em diversos tipos de situações (...). Não se pode falar de competência sem lhe associar (...) algum grau de autonomia em relação ao uso do saber. (...) As competências formuladas não devem, por isso, ser entendidas como objectivos acabados e fechados em cada etapa, mas sim como referências nacionais para o trabalho dos professores, apoiando a escolha das oportunidades e experiências educativas que se proporcionam a todos os alunos, no seu desenvolvimento gradual ao longo do ensino básico» (p. 9) ${ }^{6}$.

6 Mantiveram-se os itálicos do texto. 
Esta forma de encarar a aprendizagem exigiria, segundo creio, programas pouco prescritivos e não muito extensos, já que não seria a quantidade de conhecimentos a adquirir pelos alunos que estaria no centro do currículo, mas a capacidade autónoma de os utilizar em diferentes situações. A noção de competência procura também distanciar-se de objectivos pedagógicos definidos a curto prazo pelos docentes de cada disciplina, para privilegiar o médio e o longo prazo. Reconheçamos que, vencer inércias, modificar hábitos de trabalho individualizado e, pior, com pouca divulgação e interiorização pelos professores destas intenções, não será fácil.

Diz-se também, no mesmo texto, que as competências geográficas foram agrupadas em três domínios: a localização; o conhecimento dos lugares e regiões; o dinamismo das inter-relações entre espaços. Na verdade, esta distribuição não ocorre. Ela só vem a acontecer noutra publicação intitulada: Geografia. Orientações Curriculares. $3 .^{\circ}$ Ciclo e a distribuição por estas três categorias é confusa.

Procurando outras interpretações para a lista de competências geográficas que nos é fornecida, apresenta-se outra divisão tripartida: cinco competências muito amplas, duas relativas a conceitos e duas relativas a métodos e técnicas.

Cinco competências amplas: Desenvolver a aptidão para pensar geograficamente; curiosidade pela descoberta de territórios e paisagens, valorizando a diversidade; análise de problemas concretos do mundo para procurar soluções; reconhecimento da diferenciação entre espaços, como resultado da interacção Homem-Ambiente; reflexão sobre a experiência individual para compreender a relatividade do conhecimento geográfico; relativizar a importância do lugar onde se vive para desenvolver a consciência da cidadania.

Duas competências relativas a conceitos: Compreender conceitos geográficos para descrever localização, distribuição e inter-relações; utilizar correctamente vocabulário geográfico.

Duas competências relativas a métodos e técnicas: Organizar, analisar, tratar, apresentar e comunicar informações geográficas; utilizar técnicas cartográficas para compreender e explicar a distribuição de fenómenos.

Desta lista extraio duas conclusões.

Primeira: os autores colocaram-se num terreno demasiado vago quando nos estamos a referir ao ensino obrigatório de Geografia. Segunda: deram maior ênfase aos conhecimentos e capacidades dos alunos do que às suas atitudes perante a aprendizagem de factos geográficos, ou seja, ao interesse dessas aprendizagens, aos comportamentos como indivíduos e cidadãos num mundo complexo e em rápida mudança.

De facto, das treze competências geográficas só se evidenciam três relacionadas com "atitudes»: uma que usa a palavra «solidariedade» para com os que sofrem escassez de recursos; outra que usa a palavra "predisposição» para se referir a problemas ambientais e ao desenvolvimento sustentável; enfim, outra que usa a palavra "predisposição» e a expressão «atitude crítica» para se referir aos mass media. Das competências relacionadas com atitudes, as últimas duas remetem para o reconhecimento do outro (a «alteridade»), o que, sendo necessário, é insuficiente. 
Numa altura em que tantos docentes se queixam do desinteresse dos alunos, do elevado número que abandona precocemente a escola, em que se manifestam tantas preocupações perante a indiferença dos adolescentes face a graves problemas sociais, e mesmo dificuldades das suas famílias, quando professores e alunos se debatem com problemas disciplinares, e mesmo violência, era imperioso incentivar o desenvolvimento de competências disciplinares que diminuíssem essas dificuldades, mais relacionadas com comportamentos dos alunos do que com capacidades de aprendizagem.

A presunção de que certos valores e atitudes devem ser preferencialmente veiculados através das novas áreas curriculares transversais, particularmente a «formação cívica», é arriscada por vários motivos: os professores não receberam formação, nem sequer suficiente informação sobre as novas áreas ditas «transversais», há uma longa tradição em privilegiar a formação disciplinar e, enfim, há dificuldades em interessar os alunos por algumas dessas áreas.

\section{As novas áreas curriculares não disciplinares}

Às três novas áreas curriculares - a formação cívica, a área de projecto e o estudo acompanhado - o decreto 6/2001 atribui, no conjunto, 2,5 tempos de 90 minutos em cada ano lectivo (à excepção do $5 .^{\circ}$ ano, com 3 tempos de 90 minutos), sendo da responsabilidade de cada escola a divisão por cada uma dessas áreas.

A formação cívica é o «espaço privilegiado para o desenvolvimento da educação para a cidadania» (decreto 6/2001, artigo 5. ${ }^{\circ}$ ). Pretende-se sensibilizar os alunos para uma participação social consciente, questionando os comportamentos de cada indivíduo. Nessa área transversal devem abordar-se temas como a Educação Ambiental, os Direitos Humanos, a Educação para a Saúde, a Educação Sexual, etc.

Abordar estes problemas no ensino formal é tanto mais importante, quanto os mass media e, sobretudo a televisão, se referem a comportamentos sociais diferentes dos nossos, frequentemente com uma crítica velada a valores (às vezes uma crítica expressa), que não sejam os do Mundo dito «Ocidental».

$A$ área de projecto visa o estudo de problemas concretos, num dado contexto social. Na escolha dos assuntos a trabalhar é essencial a participação dos alunos, sob a orientação de professores de diferentes disciplinas e, de preferência, com a intervenção de outros parceiros, às vezes exteriores à escola.

A metodologia do trabalho de projecto exige interdisciplinaridade e uma interacção permanente entre teoria e prática, o que implica uma cuidadosa selecção dos temas de estudo. Quanto mais vaga e subjectiva for a proposta, mais difícil e desinteressante será para os alunos. A planificação da totalidade do trabalho, bem como a avaliação constante do decorrer do processo, são condições indispensáveis. Experiências da reforma anterior (a que se chamou «Área Escola»), não permitem previsões muito animadoras. 
O estudo acompanhado dirige-se à aquisição de métodos de estudo e de trabalho pelos alunos, tentando-se uma progressiva autonomia para aprender. $\mathrm{O}$ acompanhamento dos alunos é da responsabilidade de dois docentes de disciplinas diferentes, que constituem o que se chama um "par pedagógico» ${ }^{7}$. Não é possível fazer ainda uma avaliação consistente das experiências feitas neste domínio. A aposta parece útil. Resta saber se os docentes estão preparados para ajudar os alunos a construir uma aprendizagem autónoma.

\section{Síntese sobre a evolução recente das reformas curriculares}

A virtude potencial da gestão flexível do currículo, a que o decreto 6/2001 veio dar corpo, está na autonomia que é facultada às escolas, em certos aspectos bastante flexível. Autonomia e flexibilidade são, de facto, dois motes do novo modelo de gestão curricular. Para entendermos melhor as recentes alterações, valerá a pena sintetizar aspectos distintivos das recentes reformas do ensino em Portugal. É possível identificar quatro períodos recentes:

Até aos anos de 1970, as grandes preocupações curriculares centravam-se na aquisição de conteúdos. Insistia-se mais na memorização do que na capacidade de utilizar as aprendizagens, em situações diversificadas.

A partir da revolução democrática do 25 de Abril de 1974, situação que se prolongou até aos anos de 1980, passou a centrar-se a atenção nos objectivos curriculares, numa perspectiva comportamentalista. $\mathrm{O}$ foco estava mais no ensino do que na aprendizagem, o que, segundo alguns autores, dificulta uma gestão participada e flexível do currículo.

Desde cerca de 1990, as preocupações centram-se na tarefa, ou seja, no que o aluno é capaz de realizar a partir de iniciativas pessoais, mais ou menos acompanhadas pelos professores e a escola. Nesta etapa podemos começar a falar mais na aprendizagem do que no ensino e, também, numa avaliação participada que contempla, além dos conteúdos adquiridos, as capacidades e atitudes dos alunos.

A partir dos anos 2000, a realização autónoma de tarefas continua a estar no centro da gestão do currículo, mas pretendem desenvolver-se competências transferíveis para situações distintas. Além disso, parte dessas competências são geridas pela escola uma vez que as disciplinas perdem peso face às áreas transversais do currículo. Finalmente, procura desenvolver-se a reflexão sobre o processo individual de aprendizagem.

Algumas das intenções são de saudar, embora não sejam de fácil concretização. De facto, parece preocupante a insuficiente divulgação e muito menor interiorização pelos professores dos princípios da reforma de 2001. Estamos com receio de que as intenções fiquem no papel, já que não se prepararam os professores para as alterações pretendidas.

7 O Ministro da Educação entendeu que bastaria a presença de um só professor. Esta decisão será aplicada já no ano lectivo de 2002/2003. 


\section{A UTILIDADE DA GEOGRAFIA NO ENSINO OBRIGATÓRIO}

Uma imagem muito frequente da Geografia no começo do século XXI, é ainda a de ciência do nomear, identificar, memorizar. Ou seja, uma disciplina bastante desinteressante. Para alterar essa opinião é necessário proporcionar aprendizagens sugestivas aos actuais alunos, o que não é difícil, e é até motivador para os próprios professores. É também necessário dar maior visibilidade social a esta disciplina curricular.

A Geografia tem vários "concorrentes» no ensino informal: os concursos e outros programas televisivos, certas artes como o cinema, os vídeos, etc. O turismo de massas, como forma de dar a conhecer outras terras e gentes, é outro «concorrente». Sendo em princípio saudável para divulgar o conhecimento e o interesse pelo planeta, nem sempre se atingem esses objectivos. Será porque os geógrafos não se souberam impor suficientemente neste importante mercado de trabalho? Ou porque recusam a função utilitária da Geografia?

Quando usamos a palavra «utilidade» o que pretendemos significar? Estará subjacente a este conceito o de "utilitário», prático? Ou utilidade pode ter um sentido mais amplo e menos imediato? Dito de outra maneira: a Geografia só será útil se tiver aplicação directa e imediata? Ou será útil independentemente desse peso instrumental, porque lhe é reconhecido valor intelectual e também afectivo, social?

A educação tem utilidade intelectual e instrumental, ou seja, não depende apenas de objectivos concretos, imediatos e utilitários. A educação tem em vista o desenvolvimento dos indivíduos como seres racionais e afectivos, independentemente do interesse prático, a curto ou médio prazo. Muitos professores têm disso consciência. Mas os alunos colocam-nos muitas vezes a questão: para que serve o que aprendo na escola? Ou para que servem as aulas de Geografia? Do meu ponto de vista, o interesse prático do que se aprende no ensino de Geografia na escolaridade obrigatória deve estar presente na mente dos professores, o que não é difícil de concretizar pois quase tudo o que se passa no mundo que habitamos tem uma componente espacial. A ideia de localização está sempre presente. Mesmo quando estamos perdidos. Ou ainda mais quando estamos perdidos. O mesmo com a ideia de distância: o perto, o longe e outras distâncias: o preço da deslocação, o tempo da deslocação.

A mobilidade de hoje exige a Geografia. As rápidas mudanças no espaço terrestre exigem um saber geográfico. A Geografia está em todo o lado. Ela é indispensável para que o homem se situe no planeta onde vive, o torne uma melhor morada e sinta a Terra como espaço que lhe pertence. Há cada vez mais necessidade de uma perspectiva ética dos acontecimentos, qualquer que seja a disciplina curricular em causa.

A complexidade do mundo contemporâneo, bem como as rápidas modificações a que assistimos são um pano de fundo indispensável no ensino da Geografia. Essa complexidade, aliada à multiplicidade de campos de estudo, não facilita a vida de um professor. Tomar consciência disso é um primeiro 
passo. Para superar as dificuldades que a profissão docente nos coloca, há que procurar entender esse mundo, isto é, procurarmos ser cultos. Sem cultura não há bons professores. Mas cultura não quer dizer saber enciclopédico. Quer dizer sobretudo querer saber, saber onde e como procurar informação e comportar-se eticamente. Sem ética não há cultura, o que é às vezes esquecido.

Num mundo tão complexo como aquele onde vivemos e com mudanças tão rápidas, como ajudar os nossos alunos a pensar o futuro, questão subjacente aos seus comportamentos?

Exactamente por essa complexidade e evoluir acelerado há que evitar interpretações demasiado simplistas, muitas vezes dicotómicas: desenvolvimento/subdesenvolvimento; rural/urbano; nórdico = louro/latino = moreno; cristão $=$ «fiel»/muçulmano $=$ «infiel», etc. Por isso é imperioso procurar explicações simples mas rigorosas, tendo sempre presente que não é fácil.

Seria possível elaborar uma extensa listagem de conteúdos geográficos, necessários ao cidadão comum que, na sua maior parte, não vai exercer a profissão de geógrafo. De facto, estes serão uma pequena minoria entre os alunos do ensino obrigatório. Mais útil, porventura, do que essa longa lista de conteúdos será apresentar recursos que continuam a ser pouco utilizados, o que faremos a seguir.

Seria possível, também, organizar outra extensa lista de aspectos gerais a ter em conta no ensino da Geografia e de outras disciplinas, começando pelas questões de natureza psicológica, passando pelas que se ligam à ética, aos valores sociais e a tantos outros. Fizemos uma escolha, naturalmente criticável:

a) O ensino é apenas uma componente da aprendizagem; pode haver aprendizagem sem ensino, mas não o inverso. Ajudar os alunos a aprender é dever de todos os docentes.

b) Vivemos num continente - a Europa -, pequeno espaço geográfico, mal delimitado e socialmente em construção. Como docentes de Geografia, há que dar consciência aos adolescentes dessa realidade física e social.

c) A Europa é um espaço que acolhe múltiplas pessoas de todos os continentes. Aceitar e respeitar a diversidade étnica e cultural é um dever cívico. Mas o multiculticulturalismo não se esgota nos «estrangeiros». Perto de cada um de nós vivem pessoas diferentes. Os que vêm de muito longe - de África, do Leste Europeu, do Continente americano -, porventura mais diferentes de nós do que o vizinho, merecem tanto respeito como esse vizinho.

d) A sociedade está cada vez mais dependente da tecnologia e das formas de comunicação tecnológicas. A responsabilidade de colocar os adolescentes a par delas diz respeito a todos os docentes.

e) Os alunos mais jovens precisam de perceber porque lhes exigem o esforço de aprender. Têm de perceber uma «utilidade» mais ou menos 
próxima para o tempo que despendem na escola. Se o utilitarismo do ensino não é defensável, há que ser pragmático e mostrar aos jovens o interesse das aprendizagens que se lhes exigem.

A estas cinco sugestões de ordem geral, juntamos cinco recursos ou tarefas indispensáveis a uma aprendizagem geográfica:

a) Mapas e gráficos. Nas aulas de Geografia o manual escolar é muitas vezes o único recurso. Ora, os mapas que aparecem nos manuais são insuficientes para se desenvolver uma verdadeira «literacia» gráfica. É indispensável levar para as aulas de Geografia mapas de diferentes tipos. Desde logo, mapas de estradas, mapas de roteiros turísticos, mapas topográficos, mapas temáticos diversos: geológicos, climáticos, de solos, urbanos, etc. É forçosa a leitura e interpretação de mapas de múltipla natureza. Quantos alunos terminarão o ensino obrigatório sem terem lido senão os mapas dos manuais? Há também que solicitar aos alunos a construção de mapas, sem se cair no erro de transformar as aulas de Geografia em aulas de pintura, como às vezes sucede.

b) Atlas diversos. Costumo dizer que os atlas deviam estar para as aulas de Geografia como os dicionários para as aulas de línguas. Mas estamos muito longe de tornar os atlas recursos de uso frequente. Com muita pena, reconheço que muitos professores de Geografia não têm atlas em casa e não sabem, também, os que a escola onde leccionam possui.

c) Visitas de estudo. Entre as disciplinas que recorrem à observação, ao saber ver, a Geografia está na primeira linha. Por isso, levar os alunos para o campo, seja rural seja urbano, e ensiná-los a ler a parcela do mundo acessível, a construir significado do espaço à sua volta é indispensável. O ensino da Geografia não se pode encerrar na sala de aula, porque a realidade está lá fora. As rápidas mudanças desse mundo não são observáveis das janelas de uma sala. É proposta do actual governo tornar obrigatórias no currículo as visitas de estudo, o que apoio totalmente.

d) Jogos e simulações. É bastante frequente a ideia de que com jogos e simulações não se conseguem aprendizagens eficazes. Penso que isso é verdade na maior parte dos casos, por três motivos: são mal preparados; são mal seleccionados e raramente se avaliam as aprendizagens conseguidas. Não há dúvida de que a motivação dos alunos para realizar jogos e simulações é fácil de conseguir. Mas a dúvida persiste. Será que os alunos aprendem realmente? A bibliografia mostra que há efectiva aprendizagem por meio de jogos e simulações, melhor até do que em aulas tradicionais. Mostra ainda que a recordação a médio prazo é também mais eficaz.

e) Meios audiovisuais. Nesta expressão incluo fotografias, diapositivos, imprensa e vídeos, quer produzidos especificamente para o ensino, quer os que podemos gravar a partir da televisão. A televisão é uma presença 
constante na vida de todos, sendo particularmente importante no quotidiano dos jovens. Se queremos ensinar os nossos alunos a compreender e a melhorar o mundo em que vivem, há que usar os recursos de que todos eles se servem, tanto mais que eles não se dão conta de que é por via deles que formam as suas ideias sobre o planeta. Essas imagens moldam, mais do que se admite, a personalidade dos jovens e as suas opções de vida. Sem eles terem disso consciência, a selecção do que vêem durante muitas horas do dia tem critérios muito discutíveis (e muitas vezes dependente da escolha dos familiares). Ensinar a adquirir sentido crítico sobre os meios de comunicação social podia constituir todo um programa de Geografia no ensino obrigatório, tal a sua importância. A distinção entre ficção e realidade é cada vez mais difícil. A manipulação da informação, a recepção acrítica das mensagens veiculadas pelos media não é reconhecida pela maioria das famílias e dos jovens. Os professores de Geografia têm aí um enorme papel e muitos recursos à sua disposição. Mas é preciso começarmos por reconhecer que estamos todos muito contaminados pelas agendas mediáticas. E que, como docentes, temos de nos distanciar desses registos dos media.

Relembra-se agora uma frase de Patrick Bailey, geógrafo britânico recentemente falecido. Ele referia-se aos jovens como «a geração do supermercado». E continuava: «Isolados do mundo real, as experiências dos nossos alunos são fragmentadas e veiculadas indirectamente. A televisão ocupa um lugar central nessa experiência sensorial indirecta. Os jovens tornaram-se espectadores do mundo (e mais do que lhes fica distante do que do próximo) e não actores».

\section{CONSIDERAÇÕES FINAIS}

Retomando a proposta inicial de comparar as reformas de 1989 e de 2001, sintetizemos virtudes, dificuldades e dúvidas da última, tendo como referente a anterior.

Virtudes: a intenção de incutir uma mentalidade que passa pelo empenho pessoal e por maior responsabilização individual na gestão do currículo; a autonomia facultada às escolas em certos aspectos da organização curricular, como das cargas horárias disciplinares, das áreas transversais e de outras ocupações dos alunos; certa flexibilidade na gestão das sequências de conteúdos disciplinares; a preocupação com a reflexão sobre o processo individual de aprendizagem.

Dificuldades: a persistência de conteúdos disciplinares extensos, desadaptados às intenções expressas nos princípios desta reforma e, também, à realidade do século XXI, que exige mais «saber como encontrar informações» do que "adquirir conhecimentos»; a insuficiente divulgação da recente reforma junto dos interessados; a grande responsabilidade que é cometida aos professores na gestão do currículo, nomeadamente aos directores de turma; o previ- 
sível aumento do número de turmas a leccionar por cada docente (com um máximo de seis, o que é muito); a inoperância das listas de "competências», por demasiado vagas e, em consequência, a dificuldade de passar de um ensino centrado em objectivos para a exploração de competências, muito vagas, expressas a médio ou longo prazo.

Dúvidas: Será desejável a diminuição do número de horas de permanência na escola dos alunos do ensino obrigatório ${ }^{8}$ ? A criação de três áreas transversais obrigatórias não será ambiciosa? ${ }^{9}$

\section{BIBLIOGRAFIA}

\section{Livros e artigos}

Alegria, M. F. (no prelo) - Cambios políticos recientes en el currículo obligatorio de Geografía en Portugal. Desafíos para el siglo XXI. In Actes de Jornades: L'ensenyament de la Història i de la Geografia en temps difícíls, València, Juny, 2002.

Delors, J. et al. (1996) - Educação, um tesouro a descobrir. Ed. Asa, Rio Tinto.

Dgebs (1991) - Organização curricular e programas. Ensino Básico. 3. ${ }^{\circ}$ ciclo. Vol. I. Ministério da Educação/Direcção-Geral dos Ensinos Básico e Secundário, Lisboa.

Dgebs (1991) - Programa. Geografia. Plano de Organização do Ensino-Aprendizagem. Ensino Básico. 3. ${ }^{\circ}$ ciclo, Vol. II. Ministério da Educação/Direcção-Geral dos Ensinos Básico e Secundário, Lisboa.

Leite, C.; Fernandes, P. (2002) - Potencialidades e limites da gestão curricular local para (e na) construção de uma escola com sentido para todos. In Gestão flexível do currículo. Reflexões de formadores e investigadores. Ministério da Educação/Departamento da Educação Básica, Lisboa: 41-62.

ME (2002) - Avaliação das aprendizagens. Das concepções às práticas. Reorganização curricular. Ensino Básico. Ministério da Educação/Departamento da Educação Básica, Lisboa.

Me (2002) - Currículo Nacional do Ensino Básico. Competências Essenciais 2001. Ministério da Educação/Departamento da Educação Básica, Lisboa.

Me (2002) - Geografia. Orientações curriculares. 3. ${ }^{\circ}$ ciclo. Ministério da Educação/Departamento da Educação Básica, Lisboa.

ME (2002) - Gestão flexível do currículo. Reflexões de formadores e investigadores. Ministério da Educação/Departamento da Educação Básica, Lisboa.

8 A partir de 2001 , os alunos do $2 .^{\circ}$ ciclo passam na escola 25,5 horas por semana e no 3. ${ }^{\circ}$ ciclo 27 horas.

9 Em Inglaterra começaram por ser criadas cinco áreas transversais obrigatórias que sintetizamos: 1. A comunicação por diferentes meios; 2. A matemática na vida activa; 3. A informática; 4. O trabalho em grupo; 5. A aprendizagem individual. A experiência levou a manter uma só área transversal do currículo. 
Me (2002) - Novas áreas curriculares. Reorganização curricular. Ensino básico. Ministério da Educação/Departamento da Educação Básica, Lisboa.

Merenne-Schoumaker, B. (2001) - Compétences 2001. Savoirs et Outils (...). G.E O., 47, $24^{\mathrm{e}}$ année, Liège.

Peralta, H. (2002) - Projectos curriculares e trabalho cooperativo nas escolas. In Gestão flexível do currículo. Reflexões de formadores e investigadores. Ministério da Educação/ Departamento da Educação Básica, Lisboa: 13-22.

Perrenoud, P. (1998a) - L'approche par compétences durant la scolarité obligatoire: effet de mode ou réponse décisive à l'échec scolaire ? (2. ${ }^{\mathrm{a}}$ ed.). In Constuire des compétences dès l'école. Paris: 93-110.

PERRENoud, P. (1998b) - La transposition didactique à partir des pratiques: des savoirs aux compétences. Revue des sciences de l'éducation, XXIX (3), Montréal: 487-514.

Perrenoud, P. (1999) - Construir competências é virar as costas aos saberes?, Revista Pedagógica, 11, Porto Alegre: 15-19.

Perrenoud, P. (2000a) - Aprender en la escuela a través de proyectos: Porquê? Como?. Revista de Tecnología Educativa, XIV (3), Genève: 311-321.

Perrenoud, P. (2000b) - Construindo competências. Entrevista com Philippe Perrenoud, Universidade de Genebra. In Nova Escola. Brasil: 19-31.

Simão, A. M. V. (2002) - Perspectivas sobre as áreas transversais do currículo. In Gestão flexível do currículo. Reflexões de formadores e investigadores. Ministério da Educação/Departamento da Educação Básica, Lisboa: 31-38.

\section{Legislação citada}

Decreto-Lei n. ${ }^{\circ}$ 286/89.

Decreto-Lei n. ${ }^{\circ}$ 6/2001.

Decreto-Lei n. ${ }^{\circ}$ 156/2002. 